\title{
La fecundidad del vacío
}

\section{The Fecundity of the Void}

\author{
Héctor Sevilla Godínez \\ Universidad de Guadalajara, México \\ hector.sevilla@academicos.udg.mx
}

Lo que otorga valor a una taza de barro es el espacio vacio que existe entre sus paredes.

LAO-TSÉ

Resumen: El presente artículo trata sobre las posibilidades del vacío existencial, centrándose en sus alcances, sus alternativas y sus aportes al ser humano. Se aluden, por tanto, siete características del vacío que llena: su fuente es el desapego, conduce a la expulsión de temores, angustias y odios, surge de la aceptación, alienta la liberación de las enajenaciones, supera la univocidad y permite la distinción entre la opinión y la verdad. Además, el vacío que llena dirige al individuo al reconocimiento de sus propios límites y a la intuición de un Orden que es usualmente ajeno a la intelección.

Palabras Clave: vacuidad, desapego, liberación, nihilidad, univocidad.

Abstract: This article is about the possibilities of existential emptiness, focusing on its scope, its alternatives and its contributions to the human being. There are, therefore, seven characteristics of the void that it fills: 
its source is detachment, it leads to the expulsion of fears, anguishes and hatreds, it arises from acceptance, it encourages the liberation of alienations, it overcomes univocity and allows the distinction between our opinion and the truth. The emptiness that it fills directs the individual to the recognition of his own limits and to the intuition of the Order that is usually alien to the intellection.

Keywords: Emptiness, Detachment, Liberation, Nihility, Univocity.

Recibido: I I de agosto de 2019

Aceptado: 8 de abril de 2020 https://dx.doi.org/I O.I 5 I 74/rv.vi 3i27.493

\section{Introducción}

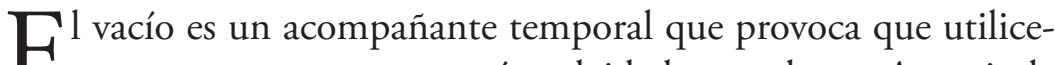
Cmos recursos que nos parecían olvidados y caducos. A partir de una adecuada experiencia de vacío, no enfrentándolo, sino permitiéndole estar el tiempo suficiente, se logra orientar la mirada hacia nuevas búsquedas y a la elaboración de proyectos creativos. En ese sentido, es posible estar en armonía con el propio caos cuando es asumido como un compañero que, más que agobiar, permite entender el orden del universo a partir de lo que nos aparece como un desorden.

Existen algunas características que permiten distinguir un vacío propicio o fecundo. Por ejemplo, es benéfico cuando un individuo es capaz de vivir con valentía la angustia derivada de un ejercicio de desapego. Asimismo, es fructífero cuando la experiencia de la vacuidad conlleva la superación de temores, angustias y odios. Por otro lado, si la persona que percibe en sí el vacío lo asume como un preámbulo a la aceptación de lo que vive, podrá facilitar para sí la 
liberación de las enajenaciones a las que es invitada cotidianamente en los contextos globales.

En la obra Fundamentos de la vía media, Nagarjuna advirtió que todo aquello a lo que se puede atribuir la condición de ser, contiene también una inclinación hacia su propio vaciamiento. En sus palabras, "lo que racionalmente puede aplicarse al vacío, se aplica racionalmente a todo. A aquello a lo que no se le puede aplicar racionalmente nada, a eso no se le puede aplicar el predicado de la vacuidad" (2011: 177).

La vacuidad no tendría que ser entendida como una gran inmensidad ajena al mundo y a las circunstancias ordinarias. La vacuidad de las cosas, su nada relativa implícita, acompaña al ser de las cosas mismas. Arnau refiere que "la vacuidad no existe fuera de la realidad convencional, es la misma realidad cuando es vista del modo adecuado" (2005: 133). De tal manera, no es necesario morir para adentrarse a la vacuidad definitiva de nuestro ser; lo que somos está navegando ahora mismo en el oleaje invisible de lo vacuo. "Todo, absolutamente todo -ya sea interno o externo- todas las sensaciones, los pensamientos, los sentimientos, los sonidos y los sabores se hallan disolviéndose de continuo" (Goldstein/Kornfielf, 2012: 52). Incluso lo que somos está dejando de ser lo que era antes y se convierte en algo distinto cada vez, al tiempo que provoca continuidad de lo que fue.

Tal como lo entiende Wilber, "la razón no puede captar la esencia de la realidad absoluta y, cuando lo intenta, solo genera paradojas dualistas" (2010: 33). La fricción entre el ser y la nada se encuentra situada en nuestra percepción dualista. Una vez que se rompe el dualismo, deviene la ruptura de distinciones; al diluirse las demarcaciones surge la intuición de que la Forma es el Vacío y el Vacío es la Forma, lo cual es expresado, por ejemplo, en $E l$ Sutra del Corazón. Esta aparente contradicción podría ser refutada afirmando que en el vacío no puede haber forma alguna, puesto 
que esta tiende a ser de tipo material. No obstante, la controversia disminuye (o aumenta) si se tiene en cuenta que la nada es la forma desde la que surge el fondo del ser.

Nishitani concebía que "la nada es lo que queda detrás de la persona; ninguna cosa sino la nada total ocupa el lugar que hay detrás de la persona” (2003: 121). Hasta aquí podría parecer que la vacuidad es una contraparte de la armonía de los seres, lo contrario a lo deseable. No obstante, cuando en la tradición oriental se hace mención de una nada absoluta se la considera como Aquello que todo lo incluye. Del mismo lo perciben los taoístas cuando reconocen que no hay cosa alguna que pueda estar fuera del Tao; de manera similar se observa en el libro de los Upanishads bajo la sentencia de que Brahma es Todo.

La experiencia fecunda del vacío deviene en una paulatina liberación de la univocidad e invita a diferenciar entre los significados y la verdad oculta en las representaciones. Cuando el vacío que llena es llevado al límite se logra concebir un orden alterno a las estructuraciones convencionales con las que se disfraza a la realidad. Por todo ello, es importante abordar enseguida las siete características del vacío fecundo.

\section{El vacío fecundo tiene su fuente al desapego}

Cuando la fuente del vacío es el desapego, aquel que es producto de un esfuerzo por soltar, dejar ir, fluir o liberarse, la experiencia de vacuidad resulta fructífera. Evidentemente, cuando la condición del vacío no es el desapego, sino la dependencia, la consecuencia resultará perjudicial. Dicho de otro modo, si un individuo persiste en su vivencia del vacío debido a que considera, siente o está convencido de que necesita irrenunciablemente a una persona, cosa, hecho u objeto para mantener su vida (o querer vivirla), tal persistencia no ofrecerá algo redituable. Por el contrario, cuando la 
persona se permite una sana distancia, una fluida desvinculación con el anterior objeto de apego, el vacío será la pauta y detonante atractivo de nuevos principios. Como puede observarse, no es el vacío un mal en sí mismo, ni mucho menos un enemigo al cual enfrentar, sino que su vivencia ocasiona una modalidad alternativa en el ejercicio de la existencia.

El desapego no es una conducta sencilla, su condición requiere de arduo trabajo y valor. Para Calderón de la Barca, poeta español, el valor es hijo de la prudencia, no de la temeridad; es por ello que el desapego implica un pausado soltarse de aquello que ata, no una enérgica disposición a la atadura. Es probable que el principal apego sea a la idea de uno mismo, la noción de un yo individual. Para Camus, "en la rebeldía, el hombre se supera en otro y, desde este punto de vista, la solidaridad humana es metafísica” (2015: 32). Visto así, el desapego a la idea del yo se evidencia en el reconocimiento de que el otro no lo es en el sentido sustancial.

El concepto sánscrito shuniata refiere la noción de que no hay algo que contenga una esencia individual, sino que todo está vacío sustancialmente. Por tanto, todo está relacionado con el resto de las realidades; las diferencias son solo ilusorias debido a nuestra precaria percepción de lo que está alrededor. Cuando no se experimenta el shuniata se permanece en un estado de adormecimiento que contrasta con el despertar que propone el budismo. Bajo esa óptica, el apego, entendido como la necesidad desmedida de que algo externo sea parte de nosotros, no tiene motivo, puesto que, de cualquier manera, existe una conexión de cada entidad con el resto y todo es parte de nosotros en cierto modo. No hay apego si se percibe el shuniata.

Más aún, en el entendido de que cada cosa existente es solo un contenedor de una realidad mayor a la que se conecta, la figuración que nos hacemos de alguien (o algo) no está antecedida por un conocimiento, sino de un desconocimiento. Nos aferramos a 
nuestras ideas de las personas más que a lo que son. Es por esto que se cree que se puede amar a alguien mientras se le está aprisionando en una etiqueta o concepto de él o ella. Es complejo soltar las categorizaciones con que hemos entendido lo que nos rodea. Una vez caídas las conceptualizaciones no hay apego posible. El despertar consiste, precisamente, en caer en cuenta del engaño que nos hemos hecho.

Nagarjuna profundizó en el concepto de shuniata y afirmó que todos los fenómenos que acontecen tienen un vacío implícito debido a que han sido derivados de forma dependiente. La comprensión correcta del vacío en todo lo que sucede conlleva una forma de nirvana en el individuo. De tal modo, el apego es la evidencia de la lejanía de una clara concepción del shuniata. Visto así, la crítica intempestiva y enérgica que se realiza al concepto y vivencia del vacío, concibiéndolo como un efecto que se produce en función a una vida sin sentido, en realidad pretende ocultar una miopía descomunal en la medida en que se maquilla de una pretendida e inquisitoria sabiduría moral.

\section{El vacío fecundo lleva a la expulsión de temores, angustias y odios}

El vacío vivido de manera fecunda, un vacío que llena, permite resignificar la ausencia; de tal modo, el temor, la angustia y el odio son desterrados de la vivencia del individuo. Por el contrario, cada uno de estos aspectos es permitido cuando se mantiene la perspectiva de que las cosas deben acontecer según la propia expectativa. El hombre y la mujer contemporáneos temen que sus vivencias no sean como esperan, por ello se desvinculan de la plenitud en su existencia. Tratan de encontrar en instantes placenteros un poco de eternidad sin tomar en cuenta que la eternidad no se forma de instantes sino que es el instante. Se teme perder el trabajo, no 
obtener el cariño de las personas amadas, desfavorecer la imagen social o desaprovechar las oportunidades de lograr lo que aún no se obtiene. Todo esto propicia automáticamente la angustia, es decir, la ansiedad derivada de comprobar que los temores estaban fundados o ver que se vuelven "realidad" justo como se buscaba evitar.

Odiamos lo que permite que nuestros temores acontezcan, persiste la angustia envuelta en el temor y el odio. Afortunadamente, la alternativa de prever el vacío nos desvincula de estas experiencias desagradables. Comprobamos que nuestros deseos no son el timón de los acontecimientos cuando un puesto laboral inseguro se perdió, la pareja que podía dejarnos nos dejó, el adversario que tenía la facultad de vencernos nos venció, las condiciones que tanta angustia provocaban se conjugaron y hasta los amigos cuya ausencia temíamos nos dejaron. ¿Qué queda después de eso? La aceptación del vacío, la resignificación de la ausencia, la visualización de la vacuidad como un nuevo punto de partida, como una oportunidad para abrirse a las alternativas, como un nuevo nacimiento. El cambio está siempre, nos guste o no, el dolor no es prerrogativa para que el cambio suceda o deje de suceder. La resignificación de lo que acontece en la vida, en el entendido del continuo vacío que todo contiene, permite desterrar el odio, la angustia y el temor.

Según Herman Hesse, escritor alemán, no ser amado es solo cuestión de suerte, la verdadera desgracia es no poder amar. En ese tenor, la desgracia no es perder a un ser en cuya presencia hemos depositado la posibilidad de amar (cualquier cosa que eso sea), sino que la tragedia se funda en que supongamos que tras la pérdida del amado somos incapaces de amar de nuevo. Todos coincidiremos en que puede hacerse una clara distinción entre el apetito y el alimento, este último nos genera un antojo pero se vuelve prescindible una vez devorado; posteriormente volverá el apetito y tendrá que satisfacerse aun cuando el banquete sea otro. Del mismo modo, la capacidad de amar no depende en forma exclusiva 
del objeto-sujeto de amor. En caso de que la dependencia fuese auténtica, la desgracia estaría consumada. Si esto no se comprende, el desasosiego queda garantizado.

No se afirma que debamos ser indiferentes a la persona que amamos o que nuestros intereses son simulaciones superfluas con las que viajamos en la vida; lo que debe quedar claro es que el temor por perder algo externo (que ni siquiera es como lo pensamos) es un absurdo. Querer poseer siempre (y que lo poseído no cambie) resulta un anhelo inocente. Cualquier relación de un individuo con algo externo a él, sea una persona, cosa o actividad, está sujeta al cambio. Los temores del padre derivados del crecimiento de una hija, que devienen en el deseo subterráneo de que permanezca en su etapa infantil, no la mantendrán siendo una nińa; la angustia del novio por tener siempre contenta a su pareja no será lo que conlleve la alegría de tal; el odio de una dama hacia todas las de su especie no garantizará que su marido deje de observarlas. El temor, la angustia y el odio son útiles solo en la medida en que originan una conducta que los modifique o, mejor, cuando permiten comprender que estamos perdiendo de vista el vacío implícito en toda interacción sostenida con el mundo exterior.

El vacío en este ámbito también permite desalojar la angustia ante la propia vida, o la sensación de que alguna culpa debe mantenerse. Tal como reconoció Mainländer: "Quien se enfrenta a la oscura noche de la muerte no se ha de culpar por los errores que cometió a lo largo de su vida, pues el mero hecho de vivir significa que cumplió con su pena antes de la muerte que le espera" (2013: 35). De acuerdo con el filósofo aludido, basta con haber vivido para haber cumplido una condena. No es necesario sumar alguna más por el cómo de nuestra existencia.

Por otro lado, ninguna ausencia debe ser totalmente desagradable si se considera la presencia que la antecedió. Dicho así, si algo o alguien que estaba ya no está, al menos podemos asegurarnos 
de que disfrutamos todo lo posible su estancia pasajera, lo cual es preferible a su ausencia total. En una palabra, la aceptación es lo que permite resignificar las ausencias y logra vencer la persistencia del temor, la angustia y el odio.

\section{El vacío fecundo surge de la aceptación}

Es fundamental distinguir la aceptación y el conformismo. Usualmente se concibe al conformismo como una consecuencia de un posicionamiento mediocre ante la vida, los anhelos no implican trabajo y el esfuerzo se desvanece debido a la inconsistencia de los proyectos o de las planeaciones. Existe una actitud conformista cuando algo que es lograble (y además se desea) se deja ir por temor al compromiso o a las responsabilidades que conlleva; asimismo, la aceptación del límite se distingue de la apatía hacia la consecución de las metas.

La aceptación, el sano desistir, supone una irremediable circunstancia que no es posible mantener. La aceptación proviene de la renuncia a la idea de que todo depende de nuestras propias fuerzas. Saberse pequeño ante el cosmos no es sinónimo de bajar los brazos, sino prepararlos para aquello que sí es posible poseer. Además de las ocasiones en que ya no es posible continuar con nuestros proyectos (por algún motivo que está fuera de las propias manos) también es posible, aun pudiendo, elegir detener la persecución de un interés cuando este nos deja de interesar.

Aceptar que hemos cambiado de opinión puede parecer simple, pero no lo es; en ocasiones existe una culpa derivada de un cambio de mirada, aunque tal situación sea honesta. En esa prerrogativa, la aceptación del propio derecho al cambio (de opinión, de intención, del gusto o del interés) es permitirse reconocer el vacío de la anterior situación. Si logramos vaciarnos de la intención que antes nos movía será porque se ha elegido dejar de simular y comenzó 
la aceptación. En tal entendido tienen resonancia la conclusión de que "el sabio sabe que las cosas ni surgen ni cesan, solo aparecen y desaparecen, como si de ilusiones se tratara" (Arnau, 2005: 79). De tal modo, incluso aquello en lo que se ha depositado nuestra razón entera podría ser también puesto en duda. Reconocer semejante fragilidad sigue el ritmo de la vacuidad de los conceptos.

También hablamos de aceptación sana cuando asumimos responsablemente las consecuencias de actos anteriores, ejercemos con constancia lo que se deriva de nuestros proyectos personales o reconocemos que los demás (o la naturaleza) no tienen la obligación de complacernos. Una sana aceptación conlleva una mejor convivencia con el entorno del cual formamos parte. No hay pérdida en aceptar la ganancia ajena, tampoco la hay en el reconocimiento del valor de los juicios contrarios o las capacidades diferentes.

Por más que intentemos declarar la guerra a la vejez, tenemos una cita inaplazable con ella si es que tenemos la suerte de seguir con vida hasta entonces. Aceptar que somos entidades móviles en un mundo móvil habla de la apología del vacío. Nuestra juventud se vaciará por completo.

La aceptación de los hechos cuyo dolor es inconmensurable en nuestra experiencia es también sinónimo de empoderamiento al perder el poder. La muerte de un ser amado, la enfermedad de un hijo, el quebranto ante la fragilidad que constatamos día a día, son todas oportunidades para la práctica de la aceptación. El duelo es posible cuando la aceptación es permitida; el dolor transfigura y aporta la línea en cuya posición se crean nuevos significados. Las olas de la vulnerabilidad pueden derrocar un apacible atardecer playero, pero poco se obtendría de maldecir al agua que nos derrumba. Mucho mejor es aceptarnos como seres líquidos en el mar de nuestra existencia. 
El número y profundidad de nuestras aceptaciones es proporcional a la inclusión y convivencia fructífera con el vacío. Tal como afirmó Thomas Storrow, reformador estadounidense, la fortaleza va creciendo en proporción a la carga. Probablemente la carga principal que debe aceptarse inicialmente es la de ser un humano. No se trata de una carga que supone sufrimiento, pero sí es algo que se ha ańadido a nuestra esencia vacua desde la cual surgimos al principio de todo.

\section{El vacío fecundo nos alienta a liberarnos de las enajenaciones}

La enajenación es un proceso de sometimiento que un sistema ejerce sobre un individuo, condicionando sus estructuras de pensamiento y sus elaboraciones críticas hasta el punto de creer la fantasía de que sus conclusiones son derivadas de un proceso estrictamente autónomo.

La vivencia oportuna de un vacío auténtico permite convivir con la propia ignorancia y no obstaculiza el reconocimiento de los propios límites racionales. En tal condición, la persona no se denomina plenamente autónoma ni se pretende totalmente autosuficiente. Liberarse plenamente de la enajenación supondría dejar atrás sus modalidades implícitas, entre las cuales se incluyen la enajenación social, la familiar, la económica, la religiosa y la afectiva.

La liberación de la enajenación requiere que el individuo admita que los convencionalismos con los que vive relacionado son aspectos que tienen un sentido dependiente de su adjudicación subjetiva; las convenciones tienen el valor que el individuo les confiere. La fijación por relacionarse con el linaje o la importancia del apellido sucede en la medida en que quien así lo considera no haya hecho algo realmente trascendente con su propia vida; tal como 
concebía Giacomo Leopardi, filósofo italiano, los antepasados son lo más importante para quien no ha hecho nada.

El patriotismo bien entendido no supondría divisiones territoriales, sino solo diferencias culturales. Saberse habitante del mundo disminuye el efecto de las distinciones apreciativas tan altamente diseminadas. Es necesario distinguir el vacío implícito en la postura estricta de considerar la nacionalidad de un individuo como un elemento distintivo de su sustancialidad; para superar la enajenación que nos lleva a discriminar se requiere de la ubicación del vacío en las supuestas distinciones sustanciales.

Respecto a la pertenencia a un sistema familiar, Ralph Waldo Emerson, ensayista estadounidense, consideraba que los hombres son lo que sus madres les hacen. Sin intentar negar la influencia intransferible de la familia en el pensamiento, la estructura cognitiva y la formación de la personalidad de un individuo, es de fundamental importancia aceptar el vacío parcial persistente en la relación humana de todo hijo con sus padres, hermanos y el resto de familiares.

La ausencia física de los padres no representa lejanía con su legado, su separación promueve cercanías abstractas o adyacentes que se perpetúan por el resto de la vida de los hijos. Existen vacíos ineludibles en todas las relaciones; el reconocimiento de tales vacíos, implícitos en la relación paterna o materna, es un elemento de vital importancia que, lejos de transferir a los padres la responsabilidad de las conductas de sus hijos adultos, permite a estos ejercer una aceptación sana y un reconocimiento de la labor de enmendadura que les corresponde. Adentrados en ese camino, es posible descubrir que algunos de los valores propuestos por la familia, o sus voces de autoridad, son maquillajes de los defectos implícitos en la misma. La búsqueda de los valores no hace más que mostrar la necesidad de los mismos debido a la precariedad de la experiencia de quien los busca. 
Con esto no se intenta promover una nueva categorización de los valores ni distinguir una línea moral desde la cual distinguirlos; por el contrario, el interés es hacer notar que los valores no se buscan, sino que se producen. Los valores no están previamente establecidos, sino que podemos elaborar valoraciones desde las cuales definir el camino de la vida y la experiencia. Dicho más claramente: ninguna familia transmite valores a sus miembros, sino que los habitúa a una estructura crítica particular desde la cual elaboran las valoraciones que matizan los juicios a través de los cuales conciben el mundo con el que se relacionan. Cuando se reconoce el hueco, fragilidad e imperfección de tal estructura, realizando una apología sana del vacío, se obtiene el logro de reconocerse sin valores; así, en el punto preciso en que el individuo se ha vaciado de todos los valores está preparado para saberse con la capacidad de elaborarlos, crearlos, definirlos y otorgarles un nuevo significado a partir de distintos ejercicios de deliberación. Esto supone, obviamente, romper con la enajenación familiar, sin que esto reste importancia a la herencia global que de tal colectividad se ha recibido.

Otra característica propia de una sana experiencia del vacío es la liberación de la enajenación afectiva, la cual, muy relacionada con el apego, oscurece la visión del individuo hasta hacerlo concluir que solo recibirá afecto exclusivamente de una sola persona. Esta dependencia, muchas veces ańeja, enloda el fluir natural de las relaciones humanas y genera que ambas partes terminen por cosificarse; asimismo, la enajenación acontece cuando la codependencia deviene en mutua confluencia y los sujetos son distorsionados por la quimera que cada uno ha fabricado del otro al que dice amar. La enmendadura es posible si se logra aceptar que nos hemos relacionado con una creación personal, con una etiqueta, no con una persona real que difiere de la idea o imagen que a su asociación hemos derivado. Sin embargo, la aceptación anterior solo sucede en los casos en que se tiene el arrojo de asumir el vacío consecuente. 
Conocer a otra persona, más que anticipar sus conductas futuras, es descubrir el maquillaje que ficticiamente le hemos añadido. La pretensión de conocer a otro, y encima querer cambiar lo que no nos guste de él, es fruto del temor al propio cambio y reconocimiento. Realizar un ejercicio de desprendimiento conceptual es el primer paso para lograr una liberación a partir de la herramienta de la ignorancia. Es por eso que cuando se refiere la expresión "poner la mente en blanco" no se está abrazando pasivamente la ignorancia, sino que se admite el deseo de expulsar las ideas erróneas sobre lo que está alrededor o, específicamente en este caso, las ideas sobre el otro.

Un interesante preámbulo para el olvido de los juicios globales sobre lo que nos circunda es ofrecido en la práctica del Mindfulness, la cual, según Thich Nhat Hanh, consiste en ofrecer una atención plena a lo que se vive en el instante en que la vivencia sucede. La plenitud derivada de experimentar la totalidad del instante fugaz que se pasea frente a los propios ojos está asociada a la apología del vacío y a la búsqueda honesta de la expulsión de contenidos innecesarios en nuestra cosmovisión.

Según Dale Carnegie, escritor y empresario estadounidense, podemos hacernos felices si actuamos como si lo fuéramos. Eso no es una superficialidad, siempre y cuando se considere que toda actuación conlleva soltar lo que no es afín con el rol actuado. La felicidad sucede en la percepción de las cosas y el significado que se genera a partir de lo que sucede, no en lo que efectivamente acontece. Cioran, el filósofo rumano, reconoció que "un filósofo solo puede evitar la mediocridad mediante el escepticismo o la mística, esas dos formas de la desesperación frente al conocimiento" (2012: 49), aludiendo con ello que la linealidad en el pensamiento y la conclusión de que se es sabio no muestra más que la equivocación de quien, creyéndose libre, solo se ata a un conjunto de ideas. 


\section{El vacío fecundo libera de la univocidad}

El vacío, cuando es permitido y vivido con aceptación, se vuelve fecundo, preñado de sentido, es un vacío que llena. Debido a la multiplicidad de posibilidades que contiene, deviene en aceptación de la variedad, contradice las posturas univocistas y enaltece la sana polivocidad.

En tal coyuntura de enfrentamiento a la linealidad se rompen la tradición de los sistemas totalitarios o absolutistas que controlan el proceso de discernimiento de los individuos. Cuando el vacío es vivido con sabiduría contiene la aceptación de las alternativas y la ruptura de la secuencia impositiva de una obligatoriedad. Entendido así, el individuo advierte que no existe una manera forzosa de realizar las cosas, que la idea de un deber ser es ilusoria y que las estructuras que forjan legalismos sociales, morales o educativos son una ficción de la cual hay que vaciarse.

Cuando se vive el vacío se modifican las interpretaciones sobre lo que significa el éxito, una buena posición o la fama superlativa; también se confrontan los paradigmas organizacionales e, incluso, se visualizan nuevos alcances de desarrollo personal en el área laboral. La experiencia del vacío rompe con la credulidad ciega depositada en las recetas o manuales sobre cómo deben hacerse las cosas o cómo debe pensarse. La persona que realiza una apología del vacío va más allá de la superficie visual, se concentra en las entrañas de lo que su alrededor le muestra; a la vez, busca desmenuzar lo que se le dice y lo que observa, sabe desconfiar pertinentemente de lo que se afirma de otros o de lo que otros señalan de él mismo. Séneca aludió que "todo lo mejor que hay para el hombre está más allá del poder humano: no se puede dar ni quitar" (1996: 47). Es por ello que la experiencia es valiosa por ser propia, porque no es una compra o regalo de otros, a diferencia de los prejuicios o los dogmas. El que vive el vacío es capaz de eliminar prejuicios, deja a 
un lado las predisposiciones (al menos la mayor parte de ellas) y se encuentra interesado en lo que no se ve a primera vista porque sabe cabalmente que las apariencias pueden engañar a un ojo novato.

En ese sentido, quien logra aliarse con el vacío es capaz de evitar diluirse en la masa global, en los valores ofrecidos mediáticamente, en los estilos de vida propuestos por la mayoría; asimismo, el individuo que acepta el vacío está abierto a la escucha y se forja competentemente en una cautelosa actitud escéptica. Bajo esa postura, el individuo no está a merced de la dirección que se le desee inculcar a través de los medios masivos de comunicación. El apologista del vacío entiende que el valor de una persona es mayor a lo que se observa, que no solo importan los resultados, que la patria misma es el universo. Cosas contrarias son aprendidas en diversas instituciones educativas cuyas propuestas didácticas están lejanas a la promoción de la crítica al sistema y, por el contrario, se busca adoctrinar a los estudiantes, quienes son vistos como inocentes aprendices que deben adaptarse a una serie de costumbres, formas y modos de actuar que, esencialmente, no les pertenecen.

Visto así, los instructores, profesores y facilitadores, así como los dirigentes de los sistemas educativos, deberían aprender, ellos mismos, que el cerebro no es un vaso por llenar, sino una lámpara que debe ser encendida para forjar luz. Esta afirmación, formulada por Plutarco, filósofo griego, ofrece una pauta particular para la enseñanza, pues no se trata de llenar de contenidos a los individuos, sino de promover el descubrimiento de los propios métodos de aprendizaje, de motivación o inspiración. Lo anterior conlleva el descubrimiento de la propia sensibilidad, proeza lograda solo a partir del sosiego y la paciencia. El vacío permite encontrar la capacidad para formular las propias herramientas y alternativas de creación. Las personas que realmente aprenden lo hacen a través de su propio camino de descubrimiento. 
La mayoría de los sistemas univocistas de educación se han centrado en el llenado de contenedores cognitivos; buscan proponer la respuesta concreta, correcta e inamovible, se cierran al hueco que provoca la creación. Los grandes descubrimientos, proezas y hazañas intelectuales se han tenido que realizar a la sombra de esos sistemas, pocas veces gracias a ellos. La notable separación entre la ocupación docente y el desempeño de indagación profesional a través de la investigación muestra que el profesor mismo, en suficientes ocasiones, hace de su labor de enseñanza una repetición de lo ya dicho anteriormente por otros; si el profesor cuenta con cierto dinamismo y habilidades didácticas, ofrecerá distintas formas de presentar la información que posee, pero difícilmente creará conocimiento a través de la investigación si no fue formado para ello.

Concluir que el proceso didáctico es un camino lineal, estructurado disciplinariamente, delimitado por contenidos específicos pre-establecidos, es evidencia de miopía ante el vacío que tal postura supone. Es oportuno partir de una conveniente ruptura con la univocidad que sostiene estos parámetros educativos reproductores y reiterativos. Si este cambio de paradigma no es logrado, se continuará afirmando en el futuro la misma sentencia de Albert Guinon, ensayista francés, quien reconoció que gracias a la educación hay menos analfabetas, pero más imbéciles.

Fundada en el aparato educativo, la idea de la felicidad se transmite culturalmente. Pocos cuestionan la afirmación de que se vive para ser felices. El anhelo de la felicidad se obstruye cuando es enfrentada con el vacío. En ese tenor, entender al vacío como un enemigo de la felicidad solo provoca lejanía del anhelo supuesto. Está claro que el vacío no nos trae la felicidad por sí mismo, pero un vacío vivido sabiamente promueve la ruptura con las ideas univocistas sobre la felicidad. Bajo esa óptica, la felicidad es una amiga imaginaria con la que uno se reconcilia al paso de los ańos, siempre y cuando la apología del vacío sea realizada, se asuman las 
carencias, se acepten los límites y se entienda lo que significa ser un humano.

\section{El vacío fecundo promueve la distinción} entre los significados y la verdad oculta en los signos

Si se vive sin la deseable distinción entre la verdad y los significados con los que catalogamos los acontecimientos, será muy probable que el fanatismo, tarde o temprano, aparezca. El caldo de cultivo de las posiciones tajantes en la afirmación de una verdad particular se sostiene cuando no se ha logrado caer en la cuenta de que la verdad misma es un signo antepuesto a la imposibilidad de poseer un control absoluto sobre la naturaleza y la realidad; evidentemente, esto se asocia con el miedo al vacío. Debido a que el control del conocimiento total no es posible, algunos individuos de las distintas etapas de la historia han creído en la posibilidad de una verdad que los provea de una respuesta universal. Sin embargo, la anhelada verdad es únicamente un signo catapultado por la conveniencia de negar el vacío. El deseo de la total objetividad es evidencia de una subjetividad que busca autoafirmarse de manera categórica y autoritaria.

Tal como aconteció en la etapa medieval, en la que se consideró a Dios como el Ser Absoluto por excelencia y se negó a la Nada por entenderla como la antítesis de Dios, suele pasarse por alto la relatividad que está contenida en la búsqueda de la objetividad. El continuo deseo de posesión de una respuesta infalible, incluido el reconocimiento social de una masa servil ante tal posibilidad, perpetúa los intentos de imposición de unos grupos a otros. La notoria ausencia de respeto en los mutuos seńalamientos entre los adversarios, lo cual acontece también en los ámbitos de lo moral y lo académico, repercute en la disminución de la disposición a diálogos constructivos y prometedores. Con poca gracia, lo que su- 
cede es un rechazo sin concesiones de la argumentación contraria y un aumento del afán de autoafirmación, lo cual atrae aseveraciones impositivas, jactancia intelectual y petulancia académica.

En Occidente usualmente se busca negar el vacío y llenarlo con ansiolíticos, medicamentos o distintos procedimientos alternativos (cuya seriedad y eficacia terapéutica es reducida) que intentan convencer al paciente, ilusamente, de que todo está bien y que la satisfacción existe sin porción de dolor. Individuos portadores de la Verdad, o de las frecuencias energéticas que vienen del más allá, aseguran que poseen el antídoto y exigen exorcizar la racionalidad de los poco cautos. La mayoría de las personas quiere una cura ante el vacío; su error consiste en comprenderlo como un estado de desarmonía que simboliza un mal. Sin embargo, la desarmonía cotidiana no es equivalente a un estado de enfermedad ni a una plaga, virus o veneno del cual haya que cuidarse.

Dicho de otro modo, la desarmonía parcial (que cada individuo contiene cotidianamente) forma parte de la armonía del universo entero. Somos piezas poco lúcidas del cosmos, constituyentes del mismo. Los momentos de vacío, particularizados muchas veces como crisis, son oportunidades de rompimiento con el orden interno problemático. De tal modo, es común la confusión de que la crisis supone desarmonía cuando, más bien, es el indicio de una desarmonía que ya estaba ahí. La crisis, o el vacío implícito ante la insuficiencia de las respuestas usualmente aceptadas, juegan a nuestro favor. La desarmonía estaba implícita antes de que fuera captada. La crisis es un síntoma oportuno de que algo debe cambiarse. De nada sirven aquí las recetas que se otorgan por razón de la autoridad o de la imposición. Bourdieu hizo énfasis en el poder simbólico, "ese poder invisible que no puede ejercerse sino con la complicidad de los que no quieren saber que lo sufren o incluso que lo ejercen" (2014: 66). Romper con los ídolos no basta, es 
necesario desacreditar a quienes los promueven y, mejor aún, la ideología que sostiene su influencia.

Los síntomas de una enfermedad en nuestro cuerpo no son los que deben enfrentarse, sino las causas que los originan. El ingreso de un virus a nuestro organismo es previo a la manifestación de los síntomas; cuando estos suceden nos logran alertar de la presencia de un virus que ya estaba ahí y que transcurrió su periodo de incubación interiormente. Los analgésicos nos han acostumbrado a buscar aminorar los síntomas sin enfrentar el problema de fondo.

La idea de lo correcto es inverosímilmente promovida por sistemas totalitarios que lo contradicen, pues lo correcto es siempre situacional y está sujeto a distintas perspectivas. El dolor es un docto instructor, siempre y cuando seamos abiertos aprendices. Cerrarse al sufrimiento es posponerlo, negar sus atributos es dejar ir la oportunidad de generar una conclusión favorable a pesar de lo desafortunadas que sean nuestras experiencias.

Romper con el orden interno lleva a la crisis y solo partiendo de ella puede obtenerse un crecimiento personal. Todo lo que modifique una estabilidad mediocre es oportuno para la mejora. De esto deriva una significación alternativa, sostenida en la idea de que el vacío es una oportunidad, una condición deseable para la reinvención, la novedad, el arrojo y la valentía.

\section{El vacío fecundo permite percibir un orden distinto a la comprensión común}

La vivencia idónea del vacío conlleva la aceptación de un más allá que escapa de la comprensión y que humanamente solo puede intuirse. Ese más allá no es necesariamente la fantasiosa representación que la mayoría de las religiones han hecho de lo que sigue a la vida humana; lejos de eso, el más allá es un orden que no corresponde a la estructuración supuestamente ordenada que el 
hombre ha hecho de lo que observa. El más allá no está tras la muerte, es una condición existente en el instante en que todo sucede. Por tanto, apologizar el vacío es reconocer la insuficiencia de las explicaciones terrenas, humanas, cognitivas, así como entrever la posibilidad de un Orden global cuya comprensión se sabe ajena. De tal Orden solo se captan leves y fugaces destellos si la percepción es amplia. En esos menesteres, la ciencia no es por sí misma la respuesta absoluta ni otorga significados definitivos, tal es una labor que el intérprete debe realizar a partir de las herramientas y conocimientos que otorga la ciencia u otras vías alternas. En ese sentido, la religión tiene un efecto negativo si es acompañada de una fe ciega que otorga conformidad gratuita ante la incertidumbre o contenta a las personas con compensaciones estrictamente sentimentalistas. Hay una evidente ocultación de los beneficios del vacío, cuestión acontecida en los distintos estadios de la historia de la humanidad; por ello, el oscurantismo, entendido como la ocultación de las posibilidades, es una obstrucción para el progreso de la conciencia.

La ciencia explica y empaqueta a la realidad en una estructuración instrumental que busca comprensión, la cual es lograda parcialmente. Apasionarse en la búsqueda es distinto a enajenarse con las explicaciones. Si bien es oportuna la pasión, la obsesión por las respuestas suele ser condicionante y deviene en tergiversación de las explicaciones. Ser capaz de encontrar el vacío en los juicios y aceptar la levedad de la comprensión humana permite una auténtica liberación de cargas. En el Bhagavad Gita se expresa con claridad que "la sabiduría permanece estable en la persona que no tiene apego por nada, en ninguna situación, que no recibe ni rechaza ninguna cosa, buena o mala que se le presente" (2009: 72); se trata, por tanto, de una actitud de aceptación sin pretensiones, tras reconocer la vacuidad de los apegos mismos. 
Es comprensible que la mayoría de las personas considera que una vida en la que se cree en el amor, los sentidos de vida y la existencia del yo es, en cierto modo, más llevadera y sencilla; por ello, no se propone que tales alternativas dadoras de motivos sean negadas o prohibidas, ni que se juzgue a aquel que crea fervientemente en ellas, pero cabe reconocer que tales significaciones están precedidas de un ansioso interés por llenar el vacío.

Relacionarse con otro sin intentar llenarse de él es mucho mejor que amar por sobre todas las cosas a quien satisface nuestra necesidad mientras se le cosifica. Construir sentidos de vida que puedan ser móviles y que no estén exentos de duda y de juicio continuo es más valiente que elegir una sola vez y querer saturar de perpetuidad la fugacidad de cada día, a pesar de que ya no se desee lo mismo. Asumir que la imagen que hemos hecho de nosotros es una efímera representación fallida y que el yo es una especie de ficción necesaria para causar una separación distintiva, aparentemente indispensable, es de mayores alcances que creer fantasiosamente que somos los que suponemos ser. Si se logra relativizar la vivencia del amor, la existencia de sentidos y la idea del yo, en esa proporción se alcanzará también un breve destello de comprensión global; sin embargo, en el momento en que tal comprensión se crea concedida, se esfumará repentinamente. Toda respuesta es una porción de aire que no puede aprisionarse, cuando se cierra el puño es expulsada de nuestro control. De tal modo, la permanencia de una respuesta coincide con el instante en que nos permite saber que se ha ido de la propia mano y que el entendimiento es fugaz.

Rudyard Kipling, novelista inglés, afirmó que viaja más rápido quien viaja solo; no obstante, avanza más prolíficamente quien se sabe parte de una totalidad que en su armonía separa y en la separación une. No solo formamos parte de una totalidad humana, sino cósmica. Esto no implica una explicación mágica de la realidad sino, propiamente dicho, el reconocimiento de la imposibili- 
dad de acceso a tal realidad, velada por las representaciones con las que esperamos acceder a ella.

\section{Conclusiones}

El vacío que llena puede reconocerse cuando tiene en su fuente al desapego; a partir de ahí permite la superación de temores, angustias y odios. Igualmente, el vacío referido surge de la aceptación y promueve la liberación de las enajenaciones que surgen cuando la aceptación no acontece. Por tanto, la vivencia sana del vacío se relaciona con una procesual liberación de los criterios univocas y permite distinguir entre los significados y la verdad detrás de los signos. Si la vivencia del vacío fecunda una posibilidad fructífera se logrará, por ende, percibir un orden ajeno a la comprensión cotidiana; es ahí, en el silencio de toda respuesta, en la insolvencia de las explicaciones, en la quietud de todo afán por llenarse, donde la crisis se vuelve un aliado reconstructivo y la ausencia se resignifica en armonía con la esencia vacua desde la cual toda evolución es permitida.

El sufrimiento por el vacío acontece cuando aún no hay un vacío realmente. Las ideas que nos hacen suponer que el vacío es negativo son las que, en principio, tendrían que ser vaciadas. El vacío íntimo, así como la Iluminación, no son metas que deba proponerse obsesivamente un aprendiz; del excesivo afán procede el éxito de las insanas invitaciones a dirigir la vida a partir de recetas y reglamentaciones para el logro de un fin particular. Más que un objetivo, el vacío es una condición a la cual se logra llegar cuando se supera la necesidad de estar ahí.

No hay un ego del cual liberarse o al cual trascender; el ego mismo es una ficción que hemos elaborado para suponernos supremos. Quien afirma que se esfuerza por trascender su ego es desde el ego mismo desde donde habla. Cuando más que un ego 
se asume que se es una presencia íntima del cosmos, se deshecha la necesidad de trascender lo material; es ahí cuando se comprende que lo terreno es una habitación, no lo habitado.

El vacío no requiere de ninguna apología. Somos los individuos quienes necesitamos apologizar al vacío para permitirnos, a partir de él, una elaboración alternativa de la propia existencia. No somos mártires del vacío ni existe una omnipotente santidad por cuyo llamado se pueda pretender la osadía de sentirse elegidos. El vacío es y no dejará de estar, no importa si lo queremos negar o aprobar. Si la apología del vacío no es realizada, los daños derivados no pueden atribuirse al vacío como si este tuviese voluntad, sino que son consecuencia de su negación, del temor que nos genera.

\section{Bibliografía}

Arnau, Juan, 2005, La palabra frente al vacio. La filosofía de Nagarjuna, Fondo de Cultura Económica, México.

Bourdieu, Pierre, 2014, Intelectuales, politica y poder, Eudeba, Buenos Aires.

Camus, Albert, 2015, El hombre rebelde, Alianza, Madrid.

Cioran, Emil, 2012, De lágrimas y de santos, Tusquets, Ciudad de México.

Goldstein, Joseph y Jack Kornfield, 2012, Vipassana, Kairós, Barcelona.

Mainländer, Philipp, 2013, Filosofía de la redención, S. Baquedano (trad.), Fondo de Cultura Económica, Santiago.

Nāgārjuna, 2011, Fundamentos de la vía media (Mūlamadhyamakakārikā), Siruela, Madrid.

Nishitani, Keiji, 2003, La religión y la nada, Siruela, Madrid.

Séneca, 1996, Consolaciones a Marcia, Gredos, Madrid. 
S/a, 2009, Bhagavad Gita, Consuelo Martin (Ed.), Trotta, Madrid. Wilber, Ken, 2010, Los tres ojos del conocimiento, Kairós, Barcelona. 